\title{
Photovoltaic Power Converter as an Input Source for SEPIC Converter
}

\author{
T.C. SrinivasaRao \\ Dept. of EEE \\ Vardhaman College of Engg \\ Shamshabad, \\ Hyderabad, India
}

\author{
Fatima Unnisa \\ PG Student Dept. of EEE \\ Vardhaman College of Engg \\ Shamshabad, \\ Hyderabad, India \\ N. Srinivas \\ Dept. of EEE \\ Vardhaman College of Engg \\ Shamshabad, \\ Hyderabad, India
}

\author{
D.Shobha Rani \\ Dept. of EEE \\ Vardhaman College of Engg \\ Shamshabad \\ Hyderabad, India
}

\begin{abstract}
The photovoltaic (PV) stand-alone system requires a battery charger for energy storage. This paper presents the modeling and controller design of the PV charger system implemented with the single-ended primary inductance converter (SEPIC). The designed SEPIC employs the peak-current-mode control with the current command generated from the input PV voltage regulating loop, where the voltage command is determined by both the PV module maximum power point tracking (MPPT) control loop and the battery charging loop. The control objective is to balance the power flow from the $\mathrm{PV}$ module to the battery and the load such that the PV power is utilized effectively and the battery is charged with three charging stages. This paper gives a detailed modeling of the SEPIC with the PV module input. Accordingly, the PV voltage controller, as well as the adaptive MPPT controller, is designed. The effectiveness of the proposed methods is proved with some simulation and experimental results. The converter achieves higher than $80 \%$ efficiency across the entire input voltage range at nominal output voltage, and maintains good efficiency across the whole operating range.
\end{abstract}

\section{Index Terms}

Maximum power point tracking (MPPT), power balance control, single-ended primary inductance converter (SEPIC), stand-alone

\section{INTRODUCTION}

MANY portable electronic applications could benefit from a power converter able to achieve high efficiency across wide input and output voltage ranges at a small size. However, it is difficult for many conventional power converter designs to provide wide operation range while maintaining high efficiency, especially if both up-and-down voltage conversions are to be achieved. Furthermore, the bulk energy storage required at contemporary switching frequencies of a few megahertz and below limits the degree of miniaturization that can be achieved and hampers fast transient response. Therefore, design methods that reduce energy storage requirements and expand efficient operation range are desirable. This paper exploit the use of resonant switching and gating along with fixed frequency control techniques to achieve these goals. The quasi-resonant SEPIC converter, resonant gate drive and associated control methods suitable $f$ or converter designs at frequencies above $10 \mathrm{MHz}$.

Solar power is more and more attractive due to the several environmental protection regulations and the predictable shortage of conventional energy sources [1], [2]. Many types of photovoltaic (PV) power conversion systems have been developed including the grid-connected system for reducing the power from the utility [3]-[6] and the stand-alone system for providing the load power without the utility[6]-[7]. The stand-alone system requires battery for energy storage to supply the load power during the period without or shortage of solar power. Because the $\mathrm{P}-\mathrm{V}$ characteristic of the PV module is varied with the isolation level as well as the temperature [8], [9], if the peak power voltage of the PV module does not match with the battery voltage, the energy conversion efficiency of the PV module will be reduced using the direct connection of the PV module and the battery. Therefore, a battery charger is required to track the peak power of the PV module in all operation conditions [10].

This paper explores the charger system implemented with the single-ended primary inductance converter (SEPIC) [11]. Although the boost converter usually has higher efficiency than the SEPIC, however, it is only applicable for cases where the battery voltage is higher than the PV module voltage. The buck-boost feature of the SEPIC widens the applicable PV voltage and thus increases the adopted PV module flexibility. The comparison of various buck -boost converters from different points inductance converter (SEPIC)[12]. Although the boost converter usually has higher efficiency than the SEPIC, however, it is only applicable for cases where the battery voltage is higher than the PV module voltage. The buck-boost feature of the SEPIC widens the applicable PV voltage and thus increases the adopted PV module flexibility. The comparison of various buck-boost converters from different points shown in Table 1. Among these converters, although the SEPIC is not the best from the views of efficiency and cost, it still has the merits of non inverting polarity, easy-to drive switch, and low input-current pulsating for high-precise MPPT that makes its integral characteristics suitable for the low-power PV charger system. This paper will investigate the SEPIC with the PV module input. The smallsignal model of such a SEPIC will be derived, and upon 
Table 1

Comparison of various buck-boost converters

\begin{tabular}{|c|c|c|c|c|c|}
\hline $\begin{array}{c}\text { Converters } \\
\text { Features }\end{array}$ & Buck-Boost & Buck & $\begin{array}{c}\text { Positive } \\
\text { Buck-Boost }\end{array}$ & SEPIC & Fly back \\
\hline $\begin{array}{c}\text { Output Voltage } \\
\text { Polarity }\end{array}$ & Invert & Invert & Non-Invert & Non-Invert & Non-Invert \\
\hline Input current & pulsating & Non-pulsating & $\begin{array}{c}\text { Depends on operating } \\
\text { mode }\end{array}$ & Non-pulsating & pulsating \\
\hline Switch drive & Floated & Floated & $\begin{array}{c}\text { One floated } \\
\text { One grounded }\end{array}$ & Grounded & Grounded \\
\hline Efficiency & Low & Medium & $\begin{array}{c}\text { High with only } \\
\text { one stage is active }\end{array}$ & Medium & Low \\
\hline Cost & $\begin{array}{c}\text { Medium due to float } \\
\text { drive }\end{array}$ & $\begin{array}{c}\text { Medium due to } \\
\text { additional } \\
\text { block capacitor }\end{array}$ & $\begin{array}{c}\text { High due to an additional } \\
\text { switch and diode, a more } \\
\text { complex drive circuit }\end{array}$ & $\begin{array}{c}\text { Medium due to } \\
\text { additional } \\
\text { block capacitor }\end{array}$ & $\begin{array}{c}\text { Low due to } \\
\text { grounded switch } \\
\text { and no block } \\
\text { capacitor }\end{array}$ \\
\hline
\end{tabular}

\section{CIRCUIT CONFIGURATION AND POWER BALANCE CONTROL OF THE CHARGER}

Figure1 shows the power stage of the proposed converter. The topology used here has some topological similarities with both the conventional SEPIC converter [17].

First, consider the circuit topology. The conventional SEPIC converter has two bulk (ac choke) inductors and yields hard switching of the switch and diode. Thus, in the conventional quasi-resonant SEPIC converter, $\mathrm{L}_{\mathrm{f}}$ is a choke inductor, selected to provide nearly constant current over a switching cycle. Multi resonant SEPIC utilizes similar bulk inductors, but explicitly introduces capacitances in parallel

with the switch and diode along with a resonant inductor in series with the coupling capacitor $\mathrm{C}_{\mathrm{s}}$ to achieve zerovoltage soft switching of the switch and diode. The design introduced here also explicitly utilizes capacitances in parallel with the switch and diode. However, in contrast to previous resonant SEPIC designs, the design here has no bulk inductors. Rather, it uses only two resonant inductors: one inductor $\mathrm{L}_{\mathrm{f}}$ resonates with the net switch capacitance, $\mathrm{C}_{\mathrm{s}}+\mathrm{C}_{\mathrm{EX}}$, for resonant inversion, whiles the other inductor $\mathrm{L}_{\mathrm{rs}}$ resonates with the rectifier capacitance $\mathrm{C}_{\mathrm{EX} 2}$ for resonant rectification. This design method leads to reduced magnetic component count, along with greatly increased response speed.

A further major difference between the converter proposed here and previous resonant SEPIC converters relates to control. The conventional resonant SEPIC converter regulates the output voltage by keeping the on-time pulse fixed while varying the OFF time duration, leading to variable frequency, variable duty-ratio operation. Unlike conventional designs which used variable-frequency. Circuit configuration of the proposed PV charger is shown in figure 2. The SEPIC converter employs the peak currentmode control with an outer PV voltage regulating loop, where the voltage command $\left(\mathrm{V}^{*}{ }_{\mathrm{b}}\right)$ is generated by combining the MPPT control loop and the battery charging loop. The combination of MPPT and charging control is for instantaneously balancing the system power to charge the battery with three stages, namely, constant-current, constant-voltage, and floating charge stages. Based on the
PV power generation, the battery SOC, and the load condition, the designed controller shown in figure 2 can operate the system in three operation modes, as shown figure 3. Figure 3(a) shows the discharging mode wherein the available maximum PV power is less than the load power. The insufficient power will be automatically supplied by the discharge of the battery. Figure 3(b) shows the partial charging mode wherein the available maximum PV power is larger than the load power and the excessive power will charge the battery, but the charging current is still less than the preset charge current Command $\left(\mathrm{I}_{\mathrm{b}}^{*}\right)$. In the aforementioned two odes, because the battery current $\left(\mathrm{I}_{\mathrm{b}}\right)$ in figure. 2, cannot reach its current command $\left(\mathrm{I}_{\mathrm{b}}{ }_{\mathrm{b}}\right)$, the signal generated by the battery current controller that is a proportional and integral (PI) controller will go positive and be limited to be zero. It results that the voltage command $\left(\mathrm{V}_{\mathrm{p}}^{*}\right)$ is determined completely by the MPPT controller, and thus, the PV module is operated in the MPPT point as shown figure 3(a) and (b). As the available peak power of the PV module is larger than the battery charging and load requirement, the battery current in figure 2 , will reach its command $\left(\mathrm{I}_{\mathrm{b}}^{*}\right)$, and the signal generated by the battery current controller will go negative and will now add voltage to increase the voltage command generated by the MPPT controller. As a result the PV module will discard the MPPT because the voltage command is shifted to a higher level than the MPPT voltage, and finally, the generated PV power will balance the load and charging requirement in the charging mode shown in figure 3(c). The charging controller is a PI controller. The limiter behind the charging controller will set the charging current command to be a maximum charging current level as the battery voltage $\left(\mathrm{V}_{\mathrm{b}}{ }_{\mathrm{b}}\right)$ has not reached its maximum charged voltage command $\left(\mathrm{V}_{\mathrm{b}}{ }_{\mathrm{b}}\right)$. In this case, and if the power condition is sufficient as figure3(c), the system will operate in the constant current charge stage. As the battery voltage approximately reaches the voltage command $\left(\mathrm{V}^{*}{ }_{\mathrm{b}}\right)$, the limiter will enter the linear region, and the charging current command $\left(\mathrm{I}_{\mathrm{b}}{ }_{\mathrm{b}}\right)$ will reduce. This stage is called the constant-voltage charge stage. Finally, as the battery voltage reaches the voltage command and the limiter output $\left(\mathrm{I}_{\mathrm{b}}{ }_{\mathrm{b}}\right)$ is reduced to be approximately zero, the battery is in the floating-charge stage, i.e., the fully SOC. Through the proposed control arrangement, the PV module will operate at MPPT, and the MPPT is discarded only when the available PV power is larger than the total power for battery charge and supplying the load. This is the most effective way for utilizing the PV power. In addition, 
the battery will not be overcharged and will stay at a high SOC voltage level if the PV power is enough. On the other hand, to guarantee no over discharge of the battery as the PV power is insufficient, a load switch controlled with a hysteretic comparator is used in figure2to disconnect the load as the battery voltage is lower than a low SOC level and reconnect the load if the battery voltage is larger than a safety level $\left(\mathrm{V} *_{\mathrm{bL}}\right)$ higher than the low SO C-level

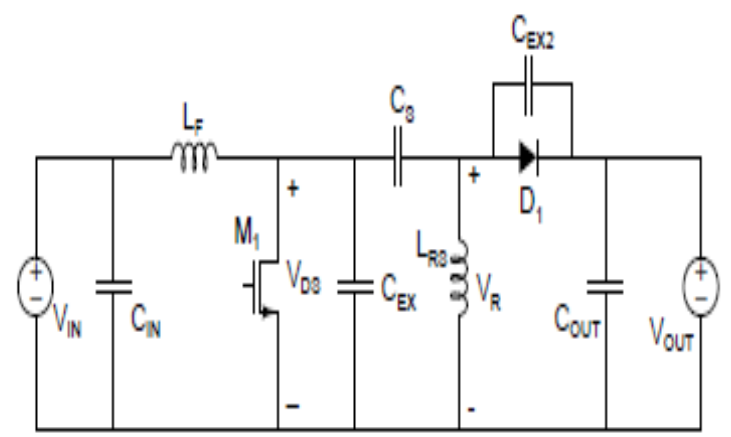

Figure 1.Schematic of the proposed resonant SEPIC converter topology

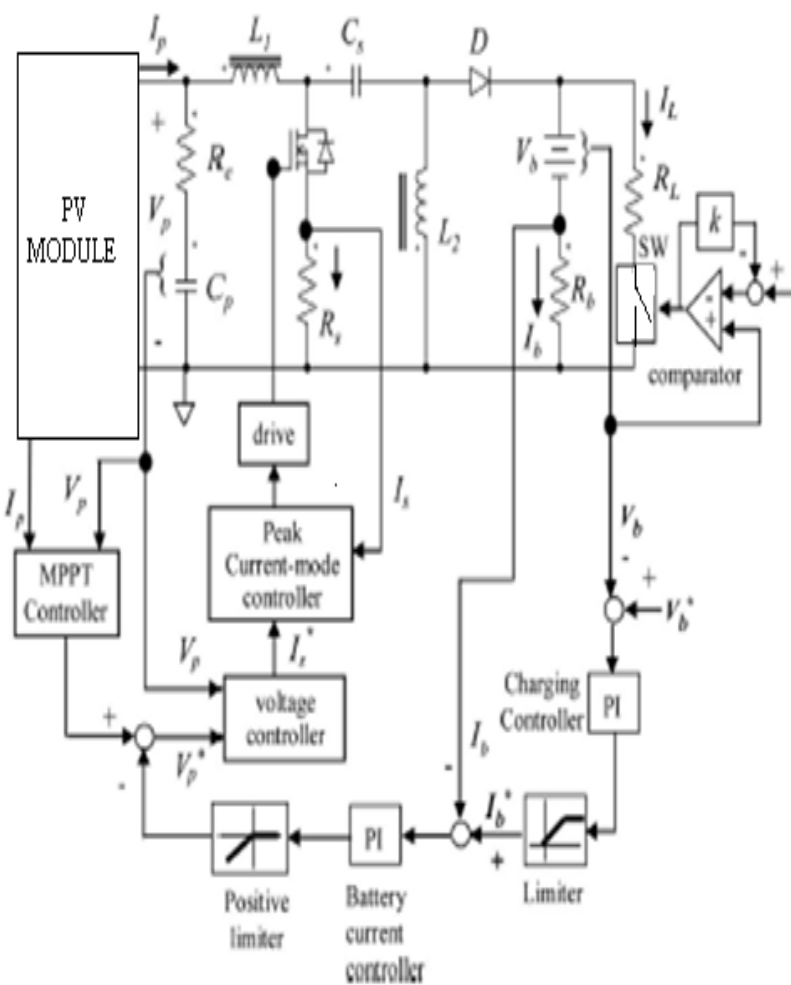

Figure2.Circuit configuration of the proposed PV charger

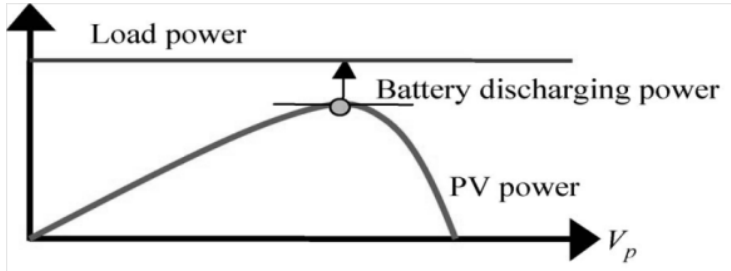

(a)

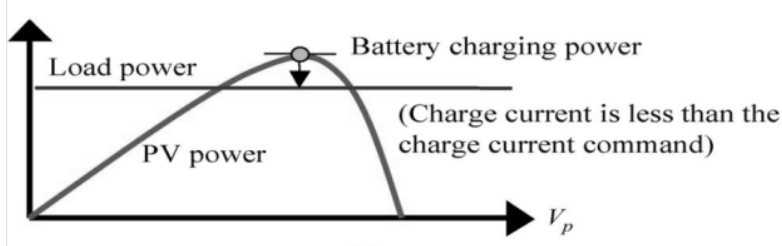

(b)

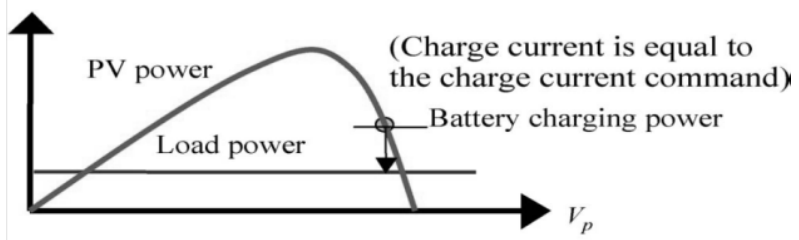

(c)

Figure3.Operation modes of charger system (a) Discharging mode. (b) Partial charging mode

(c) Charging mode

\section{MODELING AND CONTROLLER DESIGN OF CHARGER}

SEPIC is a buck-boost-derived converter that possesses a right-half-plane (RHP) zero in the continuous conduction mode (CCM), even with the peak-current-mode control in the output voltage regulation mode [12]. Following the averaged switch modeling technique presented in [12], the control-tooutput transfer function of the SEPIC in CCM withoutputvoltage regulation can be derived to be the following form:

$$
\left.\frac{V^{\prime}{ }_{B}}{D}\right|_{V^{\prime}{ }_{P}=V^{\prime}{ }_{C_{S}=0}}=\frac{V_{P}-V_{B}\left(1-S\left(D L / D^{\prime} R_{L}\right.\right.}{D^{r 2}\left(1+S\left(\frac{L}{D_{r 2} R_{L}}\right)+S^{2}\left(L C_{S} / D^{r 2}\right)\right.}
$$

where Dis the duty ratio of the switch, with $D^{\prime}=1-D$. Here, for deriving equation (1) from figure 2 , the battery is changed to be an output-filter capacitor $C_{o}$, the input voltage $V_{p}$ is changed to be a constant-voltage source, and the inductors are set to be $\mathrm{L}_{1}=\mathrm{L}_{2}=\mathrm{L}$ for simplification. Equation (1) possesses an RHP zero located at $\mathrm{D}^{\prime} \mathrm{RL} /(\mathrm{DL})$.Opposite to output voltage regulation as the conventional converter; the proposed $\mathrm{PV}$ charger regulates the input voltage. The CCM operation is preferred here for reducing the input-current ripple and reduced the switch-current stress. As will be seen in the following, opposite to the output-voltage capacitor charged by the diode current of the output regulation structure, there is no RHP zero problem of the proposed PV charger because the input capacitor current is charge controlled with the input inductor current, and the input is a PV current source for the input regulation structure. In the following, the analysis and design are based on the CCM operation mode.

\subsection{Design of Power Circuit}

Referring to figure2, the voltage transfer ratio of the SEPIC in $\mathrm{CCM}$ is [13]

$$
M=\frac{V_{B}}{V_{P}}=\frac{D}{1-D}
$$


Where $\mathrm{D}$ is the duty ratio of the switch. If the input inductor is designed based on the idea that the SEPIC is operated in CCM within the prescribed power range, then the input inductor $\mathrm{L}_{1}$ will satisfy the following relation:

where $\Delta \mathrm{i}_{\mathrm{L1}, \mathrm{PP}}$ is the peak-to-peak value of the input inductor current. $\mathrm{P}_{\mathrm{PV} \text {,min }}$ is the prescribed minimum PV power. $\mathrm{I}_{\mathrm{pmin}}$ is the $\mathrm{PV}$ module current corresponding to $\mathrm{P}_{\mathrm{PV} \text {,min. }}$. The inductor $\mathrm{L}_{2}$ is designed to couple with $\mathrm{L}_{1}$ as a fly back transformer to reduce the volume.

The turn ratio is one $\left(\mathrm{L}_{1}=\mathrm{L}_{2}\right)$ to make both inductors enter into CCM simultaneously. Substituting equation (2) into (3) results in

$$
L_{1}=L_{2}=V_{B^{2}} /\left(2 M(M+1) P_{P V, M i n} f_{S}(4)\right.
$$

The input-voltage ripple is caused by the charge and discharge of the capacitor $\mathrm{C}_{\mathrm{s}}$, as well as the ripple caused by the equivalent series resistance (ESR) of the capacitor. The electrolytic capacitor having non negligible ESR is adopted here, and the input-voltage ripple is caused mainly by it at the adopted switching frequency $(40 \mathrm{kHz})$. As a result, the input capacitor is selected based on the ESR value $\left(R_{e}\right)$ and the voltage ripple demand $\left(\Delta \mathrm{V}_{\mathrm{p}}\right)$ as

$R_{e}=\frac{\Delta V_{P}}{\Delta i_{L 1, p p}}=\Delta V_{P} /\left(2 I_{P, \min }\right)$

Once ESR is determined, the capacitance $\left(\mathrm{C}_{\mathrm{p}}\right)$ can be designed from the datasheet of the capacitor. The voltage ripple is specified with the precision of the MPPT. A larger ripple will render a larger fluctuation around the MPPT operation point. As for the coupling capacitor $\mathrm{C}_{\mathrm{s}}$, it has to flow the maximum input current pulse, and a small ESR is required for reducing the loss. In this paper, it is selected to be the same as the input capacitor $\mathrm{C}_{\mathrm{p}}$.

It should be noted that if the switching frequency of the converter is high enough such that the capacitance of the input capacitor can be reduced significantly, the tantalum and the ceramic capacitors with lower ESR can be adopted cost effectively. The design of capacitor can then be changed to be with charge and discharge of the capacitor but not with the ESR.

\subsection{Modeling and Control of SEPIC}

The equivalent circuit of the PV cell is shown in figure.4 [14], where $R_{s h}$ and $R_{s}$ are the intrinsic shunt and series resistances of the cell, respectively. Usually, the value of $R_{s h}$ is very large, and that of $\mathrm{R}_{\mathrm{s}}$ is very small; hence, they may be neglected to simplify the analysis. PV cells are grouped in larger units called PV modules which are further interconnected in a parallel-series configuration to form PV arrays. The PV array mathematical model can be represented as follows [15]:

$$
I_{P}=n_{p} I_{p h}-n_{p} I_{\text {sat }}\left[\exp \left(\frac{q V_{P}}{K A T n_{s}}\right)-1\right](6)
$$

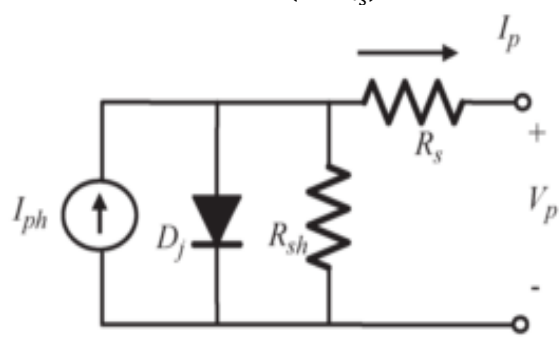

Figure4.Equivalent circuit of the PV cell.
$\Delta i_{L 1, p p}=2 I_{p, \min }=\frac{2 P_{P V, \min }}{V_{P}}=\left(V_{P} D_{M a x} T_{S}\right) / L_{1}$

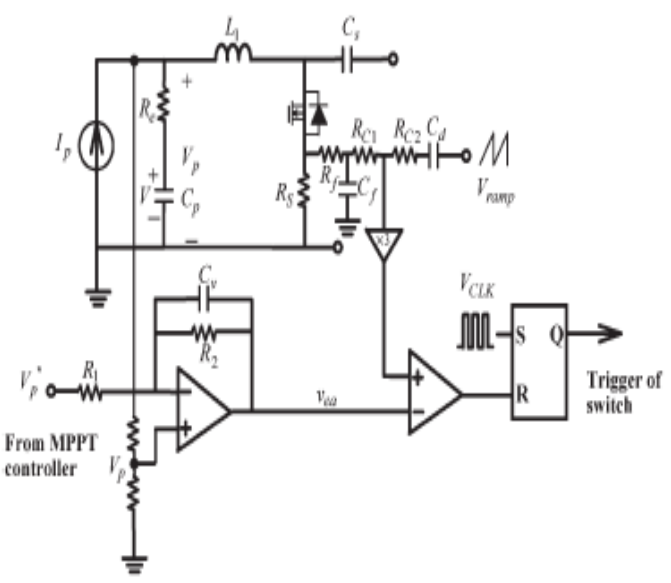

Figure 5.Feedback control of SEPIC

where $\mathrm{I}_{\mathrm{P}}$ is the $\mathrm{PV}$ module array output current (in amperes), $\mathrm{V}_{\mathrm{P}}$ is the $\mathrm{PV}$ array output voltage, $\mathrm{ns}$ is the number of modules connected in series, $n_{p}$ is the number of modules connected in parallel, $\mathrm{q}$ is the charge of an electron, $\mathrm{K}$ is Boltzmann's constant, A is the p-n junction ideality factor, T is the cell temperature (in Kelvin's), and I sat $_{\text {is the cell reverse }}$ saturation Current.

The peak-current-mode control with input PV voltage regulation of the SEPIC is shown in figure.5, where the PV module is represented as a current source

modeled byequation (6), with $n_{s}=n_{p}=1$. The PV input power is

$$
P_{P V}=V I_{P}
$$

Under a fixed isolation condition, a small perturbation of equation (7) can be found as

$P_{P V}^{\prime}=V^{\prime I_{P}}+I_{P}^{\prime} V$

Equation (8) can be rearranged to represent the small-signal expression of the PV module current.

$$
I_{P}^{\prime}=\frac{-I_{P} V^{\prime}}{V}+\left(\frac{P_{P V}^{\prime}}{V}\right)
$$

One can obtain the input capacitor current from figure.6as

$$
C_{P}\left(\frac{d V}{d t}\right)=I_{P}-I_{L 1}
$$

The small-signal expression of

$$
C_{P}\left(\frac{d V \prime}{d t}\right)=I_{P}^{\prime}-I^{\prime}{ }_{L 1}
$$

Substituting equation(9) into (11) yields

$$
C_{P}\left(\frac{d V \prime}{d t}\right)=\frac{-I_{P} V^{\prime}}{V}+\left(\frac{P_{P V}^{\prime}}{V}\right)
$$

The transfer function of the inductor current $\mathrm{I}_{\mathrm{L} 1}$ to the voltage $\mathrm{V}$ can be found from above equation as

$\left.\frac{V(s)}{I_{L 1}(s)}\right|_{p^{\prime} p v=0}=-\frac{R_{P}}{1+S C_{P} R_{P}}, R_{P}=\left(\frac{V}{I_{P}}\right)=\left(\frac{V_{P}}{I_{P}}\right)$

Where $\mathrm{R}_{\mathrm{P}}$ the equivalent load resistor seen by the $\mathrm{PV}$ module. The relation between $\mathrm{V}$ and $\mathrm{V}_{\mathrm{P}}$ can be found by considering the ESR of the capacitor as

$V^{\prime}+R_{e} C_{p}\left(\frac{d V^{\prime}}{d t}\right)=V_{P}^{\prime}$

The transfer function from $I_{L 1}$ to $V_{P}$ can be found by combining equation (13) and the transfer function of equation (14) as

$$
H(s)=\left.\frac{V_{P}(s)}{I_{L 1}(s)}\right|_{P^{\prime} P V=0}=\left(-R_{P}\left(1+s C_{P} R_{e}\right)\right) /\left(1+s C_{P} R_{P}\right)
$$

Equation (15) is a first-order system that includes a pole and a zero. The pole is determined by the capacitor $\mathrm{C}_{\mathrm{p}}$ and the equivalent load resistor $R_{P}$. As compared with that in equation 
(1), the zero here is determined by $C_{p}$ and the ESR value $R_{e}$ that is a Left-half-plane (LHP) zero. The UC3846 control IC is adopted for realizing the peak-current-mode control. The switch current is sensed with the resistor $R_{s}$. A low-pass filter formed by $R_{f}-C_{f}$ is added to reduce the leading-edge spike caused by the discharge of the internal capacitor of the switch and the diode recovery current. The slope compensation signal is added to the sensed current to prevent the sub harmonic oscillation, as the duty cycle is larger than 0.5 . The slope compensation signal is provided by the ramp signal coupled with a capacitor $\mathrm{C}_{\mathrm{d}}$. The level of compensation is adjusted with the ratio of resistors $R_{c 1}$ and $R_{c 2}$. The compensated current signal is amplified three times and then compared with the voltage error signal $\mathrm{V}_{\mathrm{ea}}$ of the voltage controller to reset the flip-flop which is set pulse by pulse by the clock signal $v_{\mathrm{CLK}}$ and to finally determine the duty ratio of the switch. Because the peak current of the inductor $L_{1}$ is the same as that of the switch, the transfer function from $V_{\text {ea }}$ to $\mathrm{I}_{\mathrm{L} 1}$ can be found as

$$
K=\frac{I_{L 1}(s)}{V_{a e}(s)}=\frac{1}{3 R_{S}\left(1+\left(\frac{m_{a}}{m_{1}}\right)\right.}
$$

Where $\mathrm{m}_{1}$ and $\mathrm{m}_{\mathrm{a}}$ are the slopes of the sensed current and the compensated signal, respectively. For assuring a stable current loop under any PV voltage, $\mathrm{m}_{\mathrm{a}} / \mathrm{m}_{1} \geq 0.5$ is chosen. Combining equations (15) and (16), the transfer function of the voltage loop can be derived as

$\frac{v_{p}(s)}{V_{e}(s)}=P(s)=K v K H(s)=\frac{\frac{-\left(K_{V} R_{e}\right)\left(s+1 /\left(C_{P} R_{e}\right)\right.}{3 R_{S}\left(1+\frac{m_{a}}{m_{1}}\right)}}{s+\frac{1}{C_{P} R_{P}}}(17)$

Where $v_{\mathrm{p}}$ is the sensed PV voltage $\left(\mathrm{V}_{\mathrm{p}}\right)$. The voltage sensing factor is $K_{v}$. The negative gain in equation (17) desires a positive feedback control of the input voltage. The low-pass filter, as in the following, is adopted as the compensator of the voltage controller

$$
G_{V}(s)=\frac{V_{C}}{V_{O}}=\frac{\frac{1}{R_{1} C_{V}}}{S+\frac{1}{C_{V} R_{2}}}
$$

Its pole is designed to cancel the zero of equation (17), i.e., $\mathrm{R}_{2} \mathrm{C}_{\mathrm{v}}=\mathrm{R}_{\mathrm{e}} \mathrm{C}_{\mathrm{p}}$. Considering that the gain and the pole will drift should be designed to satisfy the stability and provide a suitable bandwidth of the voltage loop.

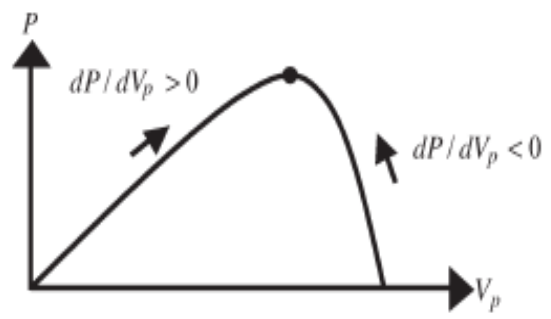

Figure6.Adopted incremental conductance

\subsection{Mppt controller design}

The proposed MPPT controller tracks the peak power of the $\mathrm{PV}$ module based on the power-voltage $\left(\mathrm{P}-\mathrm{V}_{\mathrm{P}}\right)$ characteristic shown in figure 6 and the incremental conductance algorithm [15], [16]. In the positive-slope region $\left(\mathrm{dP} / \mathrm{dV}_{\mathrm{P}}>0\right)$, the operation voltage is increased. On the other hand, in the negative slope region $\left(\mathrm{dP} / \mathrm{dV}_{\mathrm{p}}<0\right)$, the operation voltage is decreased. The peak power point starting from any operating point will be finally reached through a few steps of voltage adjustment. In this paper, for increasing the tracking speed as well as the precision, the voltage adjusting.

The peak power point starting from any operating point will be finally reached through a few steps of voltage adjustment. In this paper, for increasing the tracking speed as well as the precision, the voltage adjusting speed is slope dependent. In the positive-slope region, the adjusting speed will be slower than the negative-slope region because the positive slope is smaller than the negative slope in amplitude. The adjusting speed will be slowed down near the peak power point. This is effective to prevent the tracking oscillation near the peak power point to increase the MPPT precision.

\section{SIMULATION RESULTS}

This paper explores the charger system implemented with the single-ended primary inductance converter (SEPIC) [12], by using renewable sources. Although the boost converter usually has higher efficiency than the SEPIC, however, it is only applicable for cases where the battery voltage is higher than the PV module voltage. The buck-boost feature of the SEPIC widens the applicable PV voltage and thus increases the adopted PV module flexibility.

The comparison of various buck- boost converters from different points is shown in Table 1. This paper will investigate the SEPIC with the PV module input. The smallsignal model of such a SEPIC will be derived, and upon which, the PV voltage controller and the MPPT controller will be designed. 


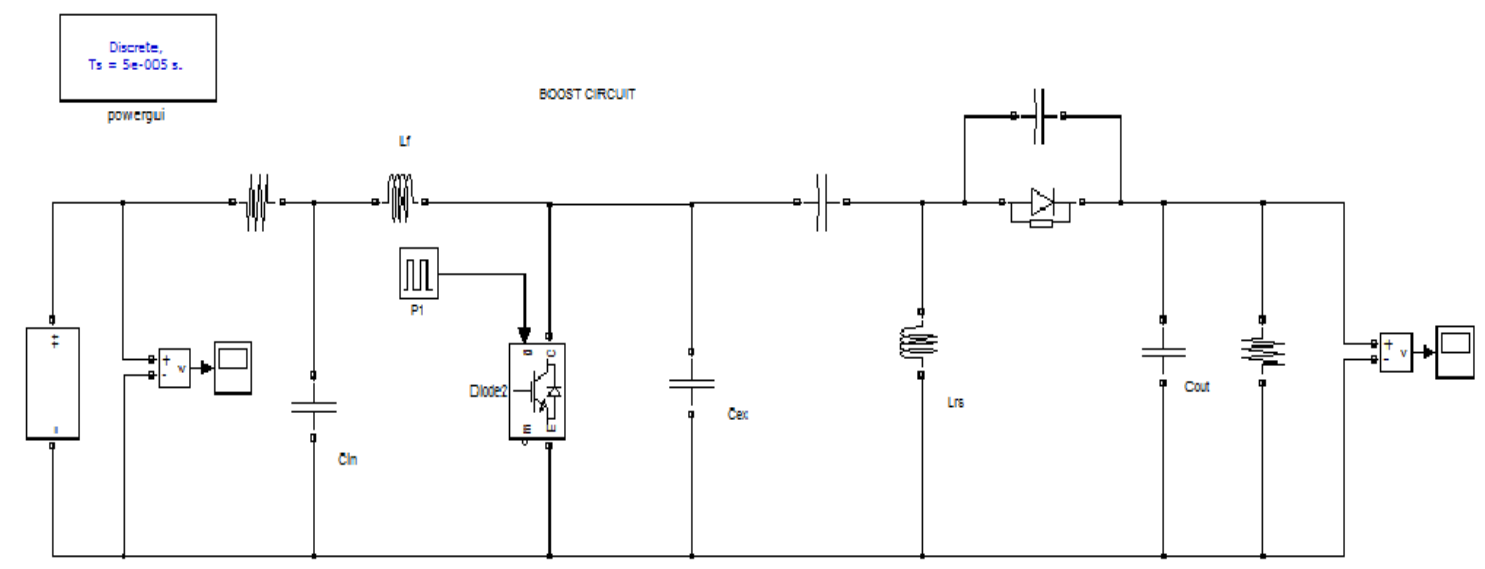

Figure 7.PV based SEPIC converter with boost operation

Where $\mathrm{C}_{\mathrm{in}}=$ input Capacitor, $\mathrm{L}_{\mathrm{f}}=$ choke inductor, $\mathrm{C}_{\mathrm{s}}=$ coupling capacitor, $\mathrm{C}_{\mathrm{EX} 2}=$ rectifier capacitance, $\mathrm{C}_{\mathrm{EX}}=$ switch capacitance and $\mathrm{C}_{\text {out }}=$ Output Capacitor.
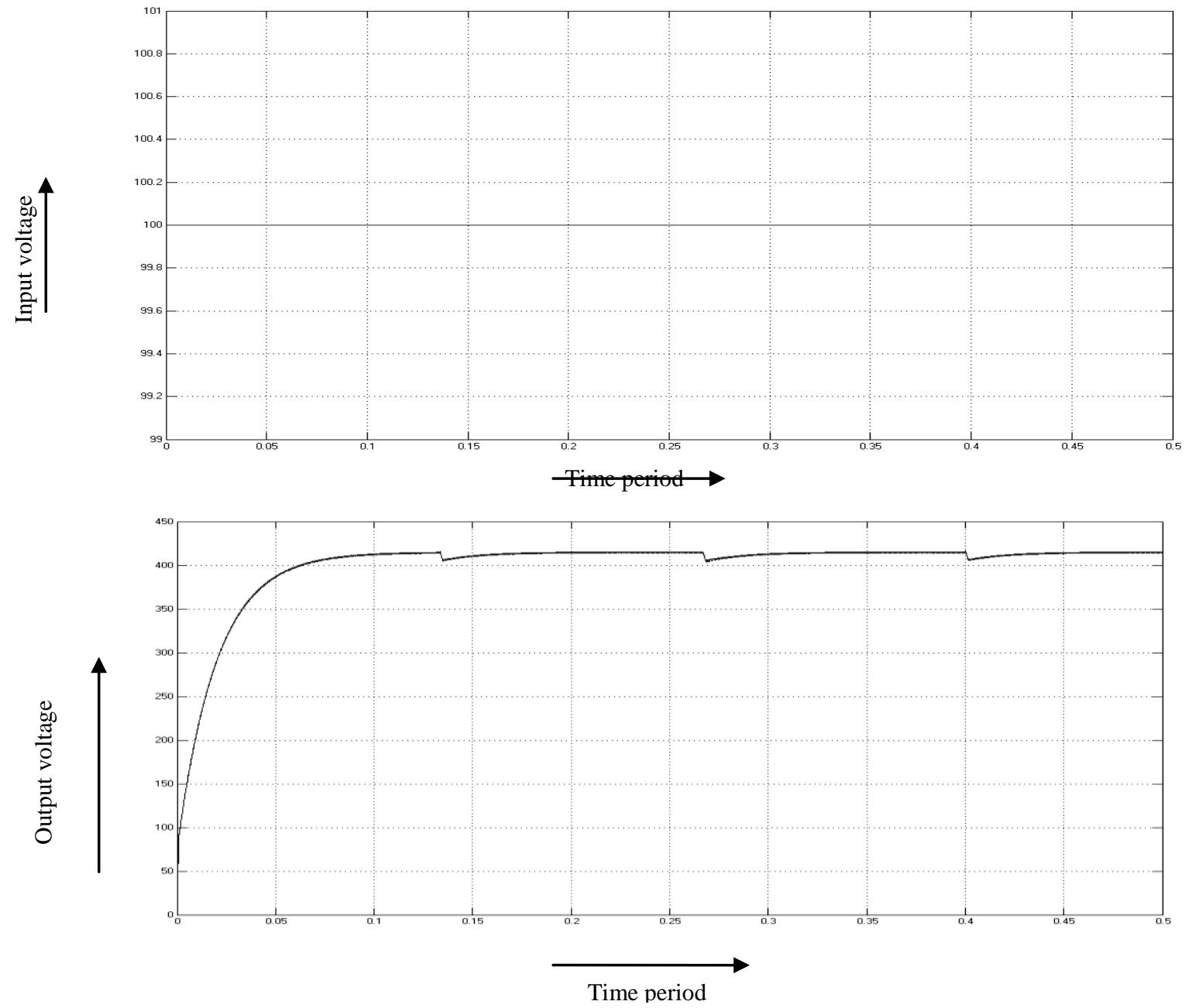

Figure 9.Output voltage of SEPIC based boost converter 


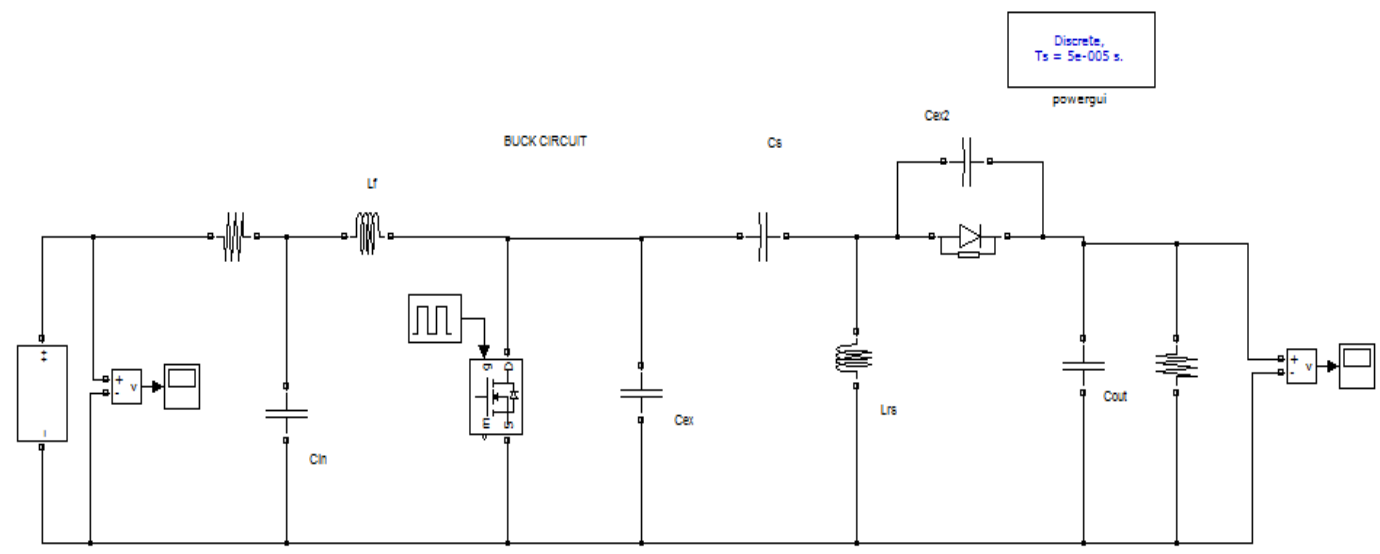

Figure 10.PV based SEPIC converter buck operation

Where $\mathrm{C}_{\mathrm{in}}=$ input Capacitor, $\mathrm{L}_{\mathrm{f}}=$ choke inductor, $\mathrm{C}_{\mathrm{s}}=$ coupling capacitor, $\mathrm{C}_{\mathrm{EX} 2}=$ rectifier capacitance, $\mathrm{C}_{\mathrm{EX}}=$ switch capacitance and $\mathrm{C}_{\text {out }}=$ Output Capacitor.

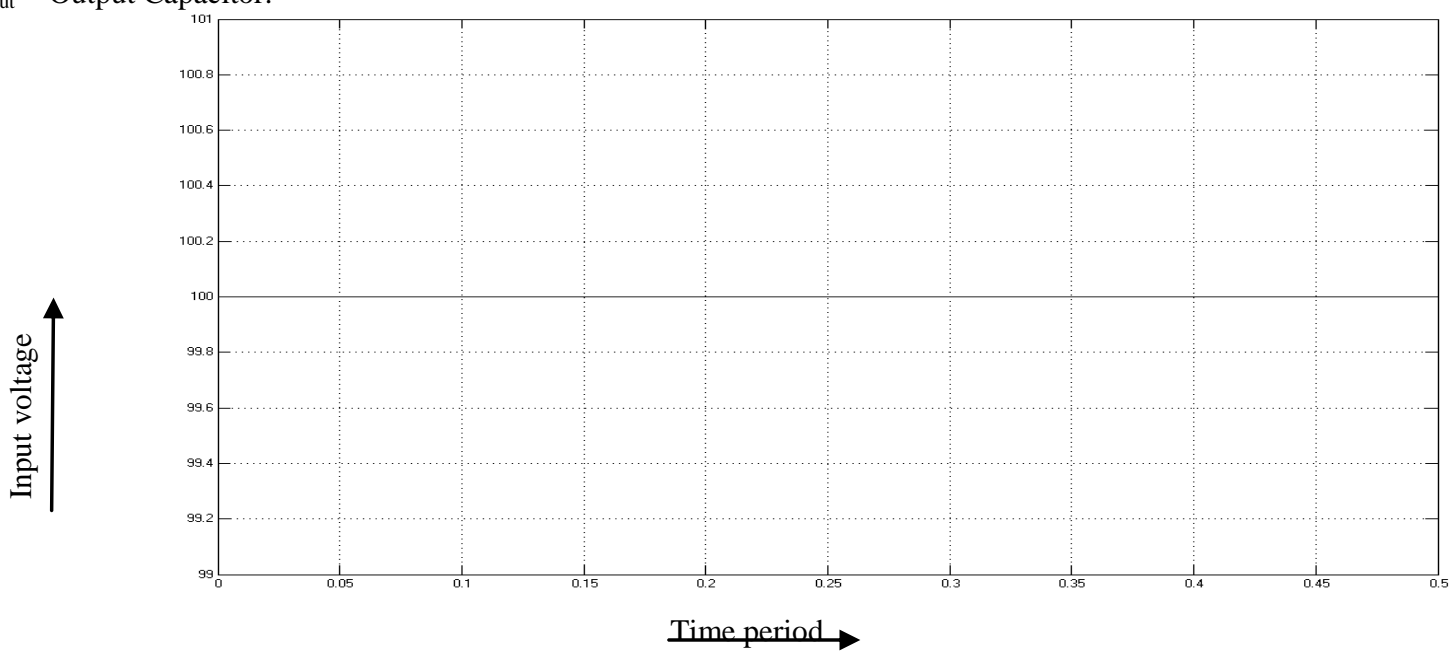

Figure 11.Input voltage of PV cell in buck converter
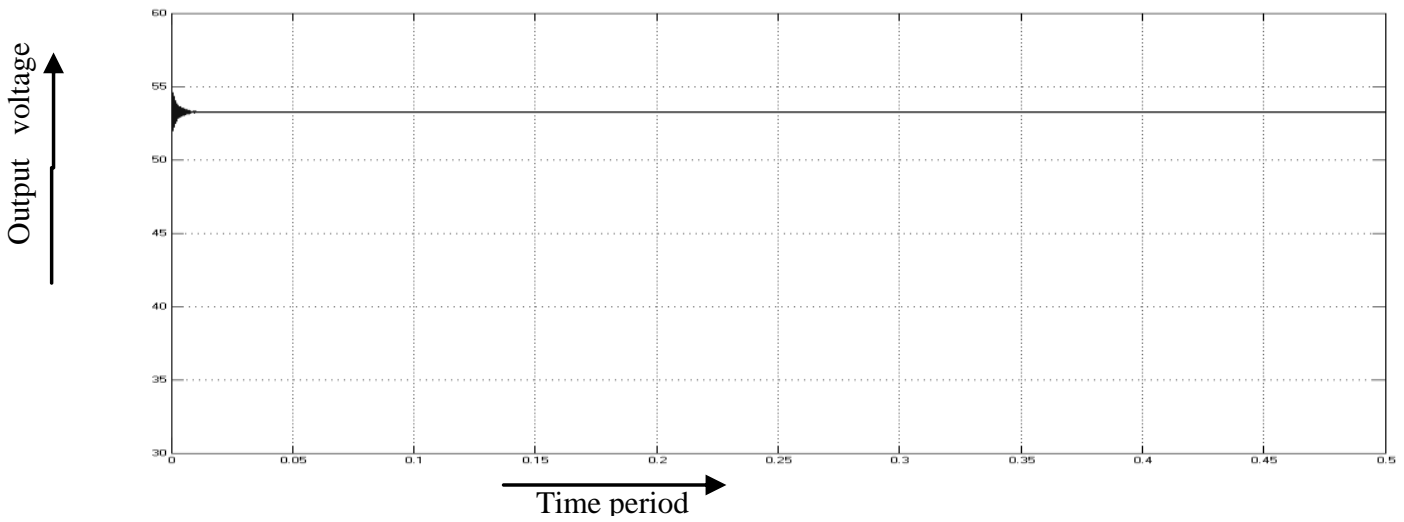

Figure 12.Output voltage if SEPIC converter in buck operation

\section{CONCLUSION}

This paper has presented a PV charger implemented with the SEPIC converter. The system has been proved to be effective in the MPPT and power balance control. The proposed modeling method of the converter with the PV module input and peak-current-mode control, the adaptive MPPT control method, as well as the power balance control method can also be applied to the charger with other types of converter. The MPPT controller was implemented with the Matlab real-time control in this paper, and it will be changed to be implemented with the microprocessor or DSP and integrated with the voltage controller and PWM to make the system more practical in the future.

\section{REFERENCES}

[1] M. Rogol,S. Doi and A.Wilkinson. 2004. Sun screen: Investment opportunities in solar power.

[2] German Advisory Council on Global Change, 2003. 
[3]S. B. Kjaer, J. K. Pedersen and F.Blaabjerg.Sep /Oct. 2005.A review of single-phase grid-connected inverters for photovoltaic modules.

[4]R.A. Mastromauro, M. Liserre, and A. Dell' Aquila. May 2008. Study of the effects of inductor non-linearbehavior on the performance of current controllers for singlephase PV grid converters.

[5] Y. K. Lo, T. P. Lee, and K. H. Wu. May 2008. Gridconnected photovoltaic system with power factor correction.

[6] H. Koizumi, T. Mizuno, T. Kaito, Y. Noda, N. Goshima, M. KawasakiK. Nagasaka and K. Kurokawa. Dec.2006.A novel microcontroller forGrid-connected photovoltaic systems.

[7] R. J. Wai, W. H. Wang, and C. Y. Lin. Jan. 2008. Highperformance stand-alone photovoltaic generation system.

[8] F. Liu, S. Duan, F. Liu, B. Liu sand Y. Kang.Jul. 2008.Avariable step size INCMPPT method for PV system.

[9] D. Sera, R. Teodorescu, J. Hantschel, and M. Knoll.Jul. 2008. Optimized maximum Power point trackerfor fastchanging environmental conditions.
[10] J. H. R. Enslin and D. B. Snyman. Jan. 1991. Combined low-cost, high-efficient inverter, peak power tracker and regulator for PV applications.

[11] D. Adar, G. Rahav, and S. Ben-Yaakov.1997. A unified behavioral average model of SEPIC converters with coupled inductors.

[12]R. W. Erickson,Norwell and MA: Kluwers. 1997 Fundamental of Power Electronics.

[13] A. I. Pressman, Switching Power Supply Design. New York.

[14]S.E. Mineiro, Jr., S. Daher, F. L. M. Antunes and C. M. T. Cruz. 2004. Photovoltaic system for supply public illumination in electrical energy demand peak, 15011506.

[15] L. Wu, Z. Zhao and J. Liu. Dec. 2007. A single- stage three-phase grid-connected photovoltaic system with modified MPPT method and reactive powercompensation, 881-886.

[16] E. Koutroulis, K. Kalaitzakisand N. C. Voulgaris.

Jan.2001.Development of a microcontroller-based, photovoltaic maximum power point tracking control system, 46-54.

[17] R. Erickson, Norwell, MA: Kluwer and D. Maksimovi'c. 2000.Fundamentalsof Power Electronics. 